\title{
Weiteres zur babylonischen Metrik.
}

\author{
Von H. Zimmern.
}

Die in Band VIII, I 2 I ff. dieser Zeitschrift auf eine Anregung GunkeL's hin von mir gegebenen vorläufigen Bemerkungen zur babylonischen Metrik haben eine mir selbst unerwartete Bestätigung erhalten durch den Text Sp. II, 265 a, auf den ich in diesem Herbst, im Begriff, eine Abschrift der salliterirenden Hymnen zu nẹtsmen, nebst den anderen gleichartigen Texten von BEzold freundlichst aufmerksam gemacht wurde, und der sich auch in Bezold's Catalogue sub K. $345^{2}$ als Duplikat zu letzterem Texte verzeichnet findet. Die daselbst gleichfalls genannten Tafeln KK. 8491, 9290, sowie K. 8463 stellen sich bei näherem Zusehen ebenfalls als Duplikate bezw. Teile desselben Textes heraus, während dies bei dem kleinen Fragment K. 14022 vorerst noch 2 weifelhaft bleiben muss. Darnach lässt sich der ganze. wahrscheinlich $25 \times 1 \mathrm{I}=275$ Zeilen lange Text zum grösseren Teile herstellen, wie dies im Folgenden geschehen ist.

Während die in assyrischer Schrift geschriebenen Tafeln KK. 3452, 8463, 849I, 9290 sämtlich continuirliche Schreibung der einzelnen Zeilen aufweisen, sind in der neubabylonisch geschriebenen Tafel Sp. II, 265 a die Zeilen durch 3 vertikale Linien in 4 Teile getheilt. Diese eigentümliche Vierteilung der Zeilen kann meiner Ansicht nach gar keinem anderen $Z$ wecke dienen, als einer Hervorhebung

Zeitschr. f. Assyriologie, $\mathrm{X}$. 
von + Versgliedern, so dass wir dadurch einen urkundlichen Beweis dafür haben, dass die Babylonier mit $\mathrm{Be}$ wusstsein in einer Gattung ihrer Poesie Verse mit ${ }_{4} \mathrm{He}$ bungen gezählt haben.

Ich gebe im Folgenden den vollständigen Text samt Transscription, obwol. ich sim Drange der Abreises insbesondere die nicht leicht $z u$ lesende und namentlich auf dem Obvers vielfach verwischte Tafel Sp. II, 265 a nicht so genau collationieren konnte, wie es wünschenswert gewesen wäre. Für den Zweck, den ich hier in erster Linie im Auge habe, nämlich den Eindruck von einem im Original nach Hebungen abgesetzten assyrischen Gedichte zu geben, mag diese erstmalige Veröffentlichung genügen, selbst auf die Gefahr hin, dass eine Reihe von Zeichen in diesem recht schwierigen Texte von mir verlesen sind. Soweit die 3 vertikalen Trennungslinien durch Sp: II, 265 a an die Hand gegeben sind, sind die Linien in der folgenden Transscription voll ausgezogen; die blos punktirten Linien rühren dagegen auf Eintragang durch mich in die nicht metrisch geschriebenen Duplikate KK. 3452, 8463, 849I, 9290 her und werden daher, namentlich an defecten Stellen, zuweilen einer Correctur zu unterziehen sein. 


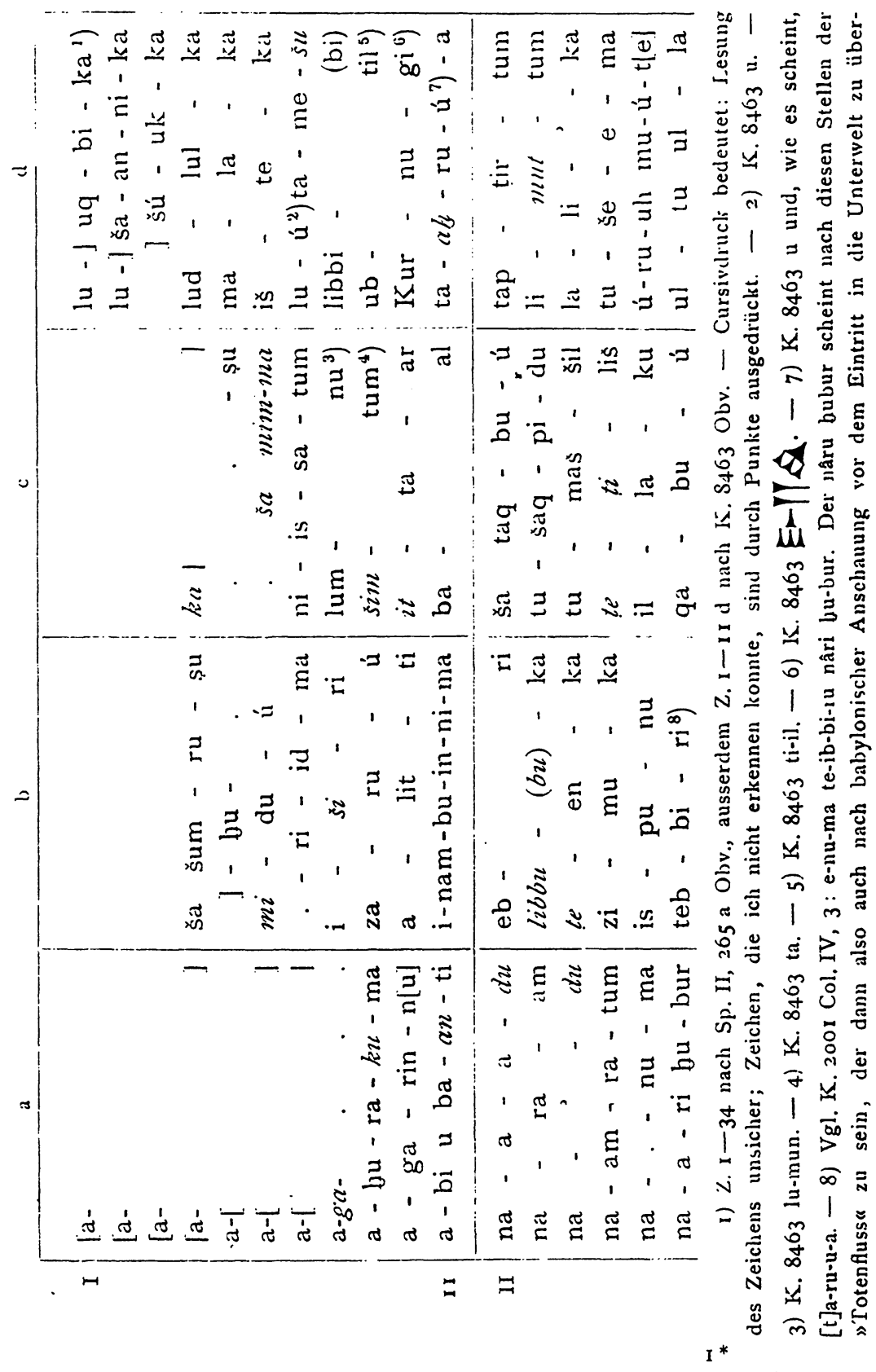


H. Zimmern

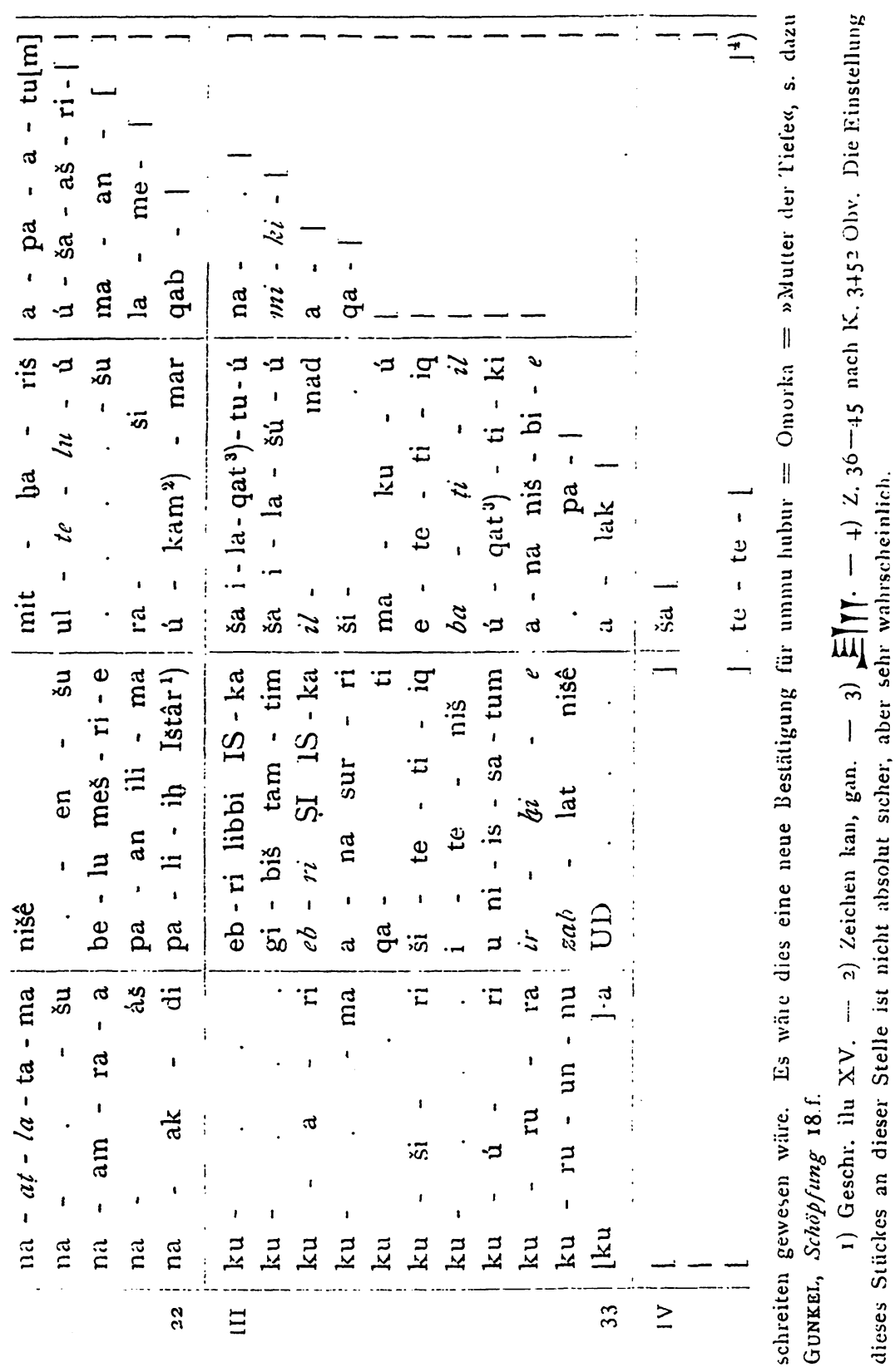




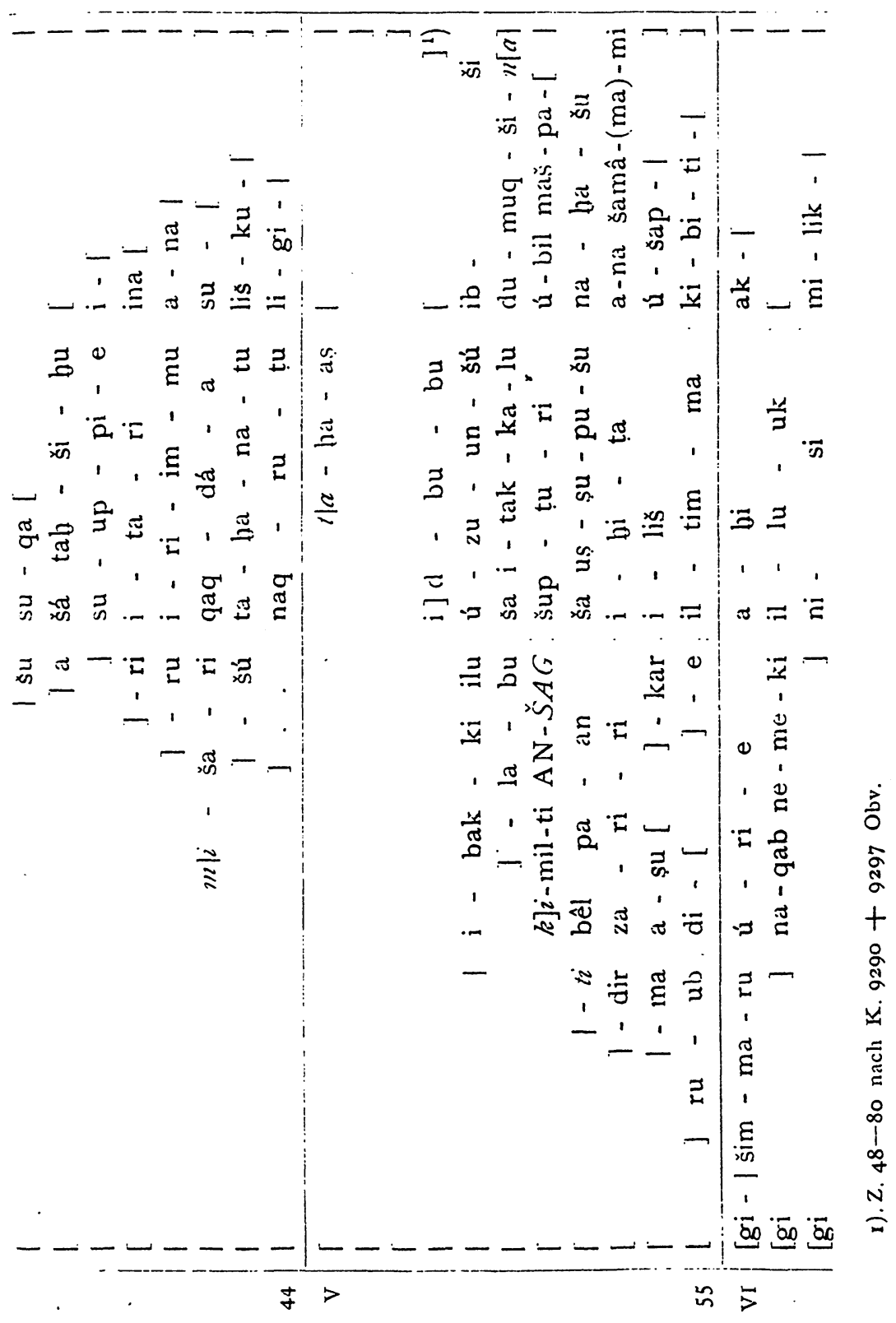


H. Zimmern

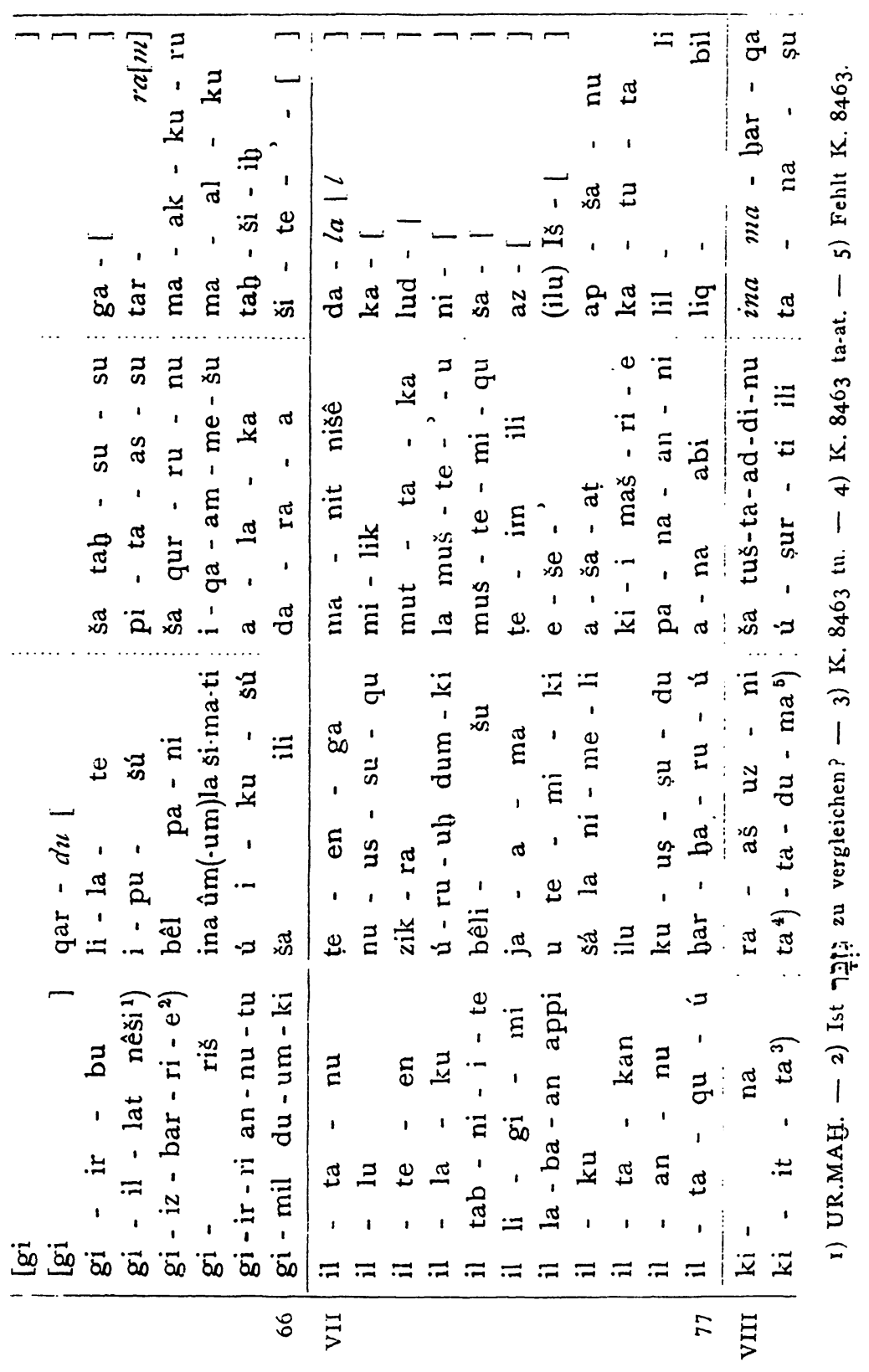


IVeiteres zur babylonischen Metrik.

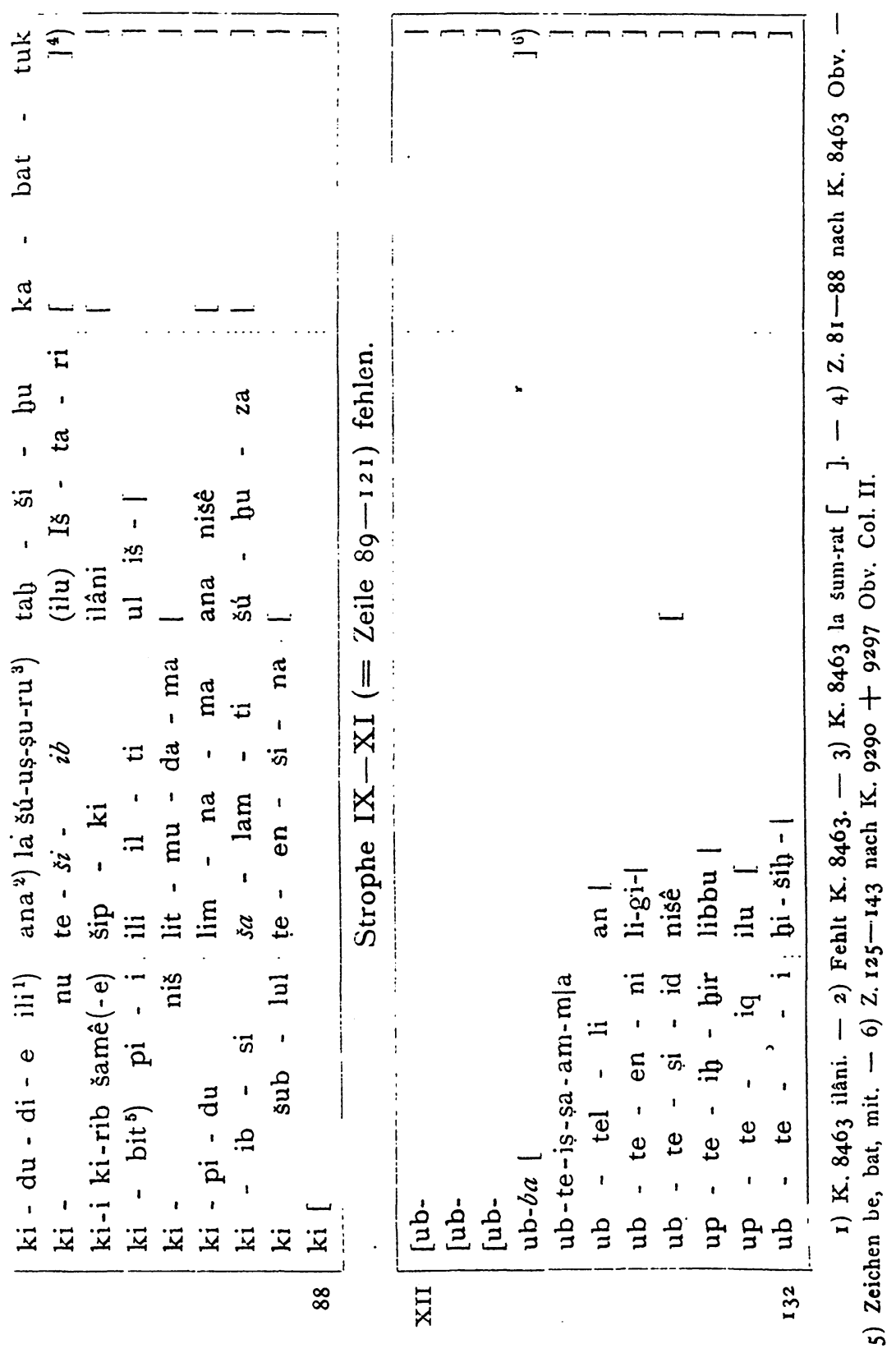


H. Zimmern

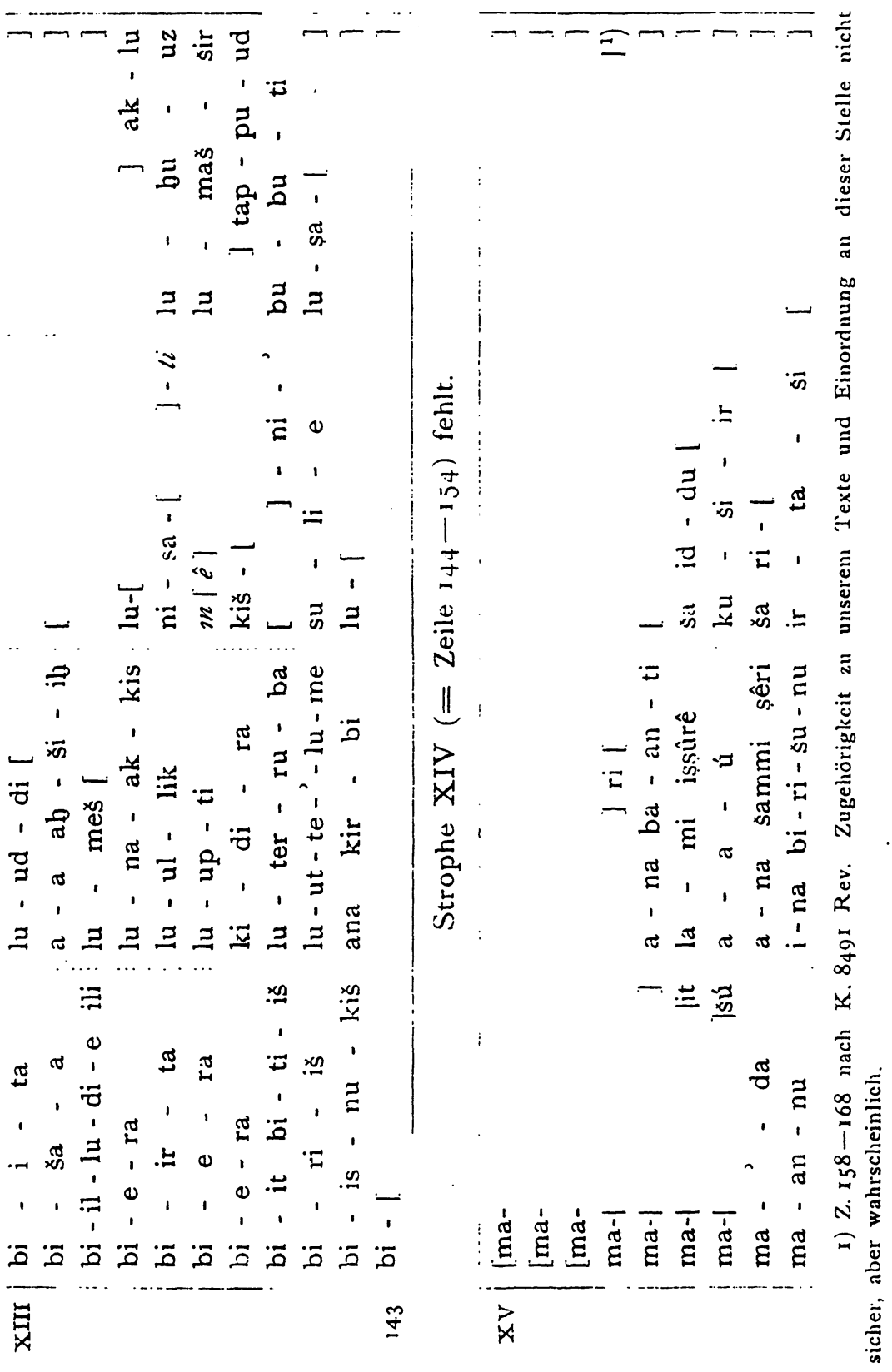


Weiteres zur babylunischen Metrik.

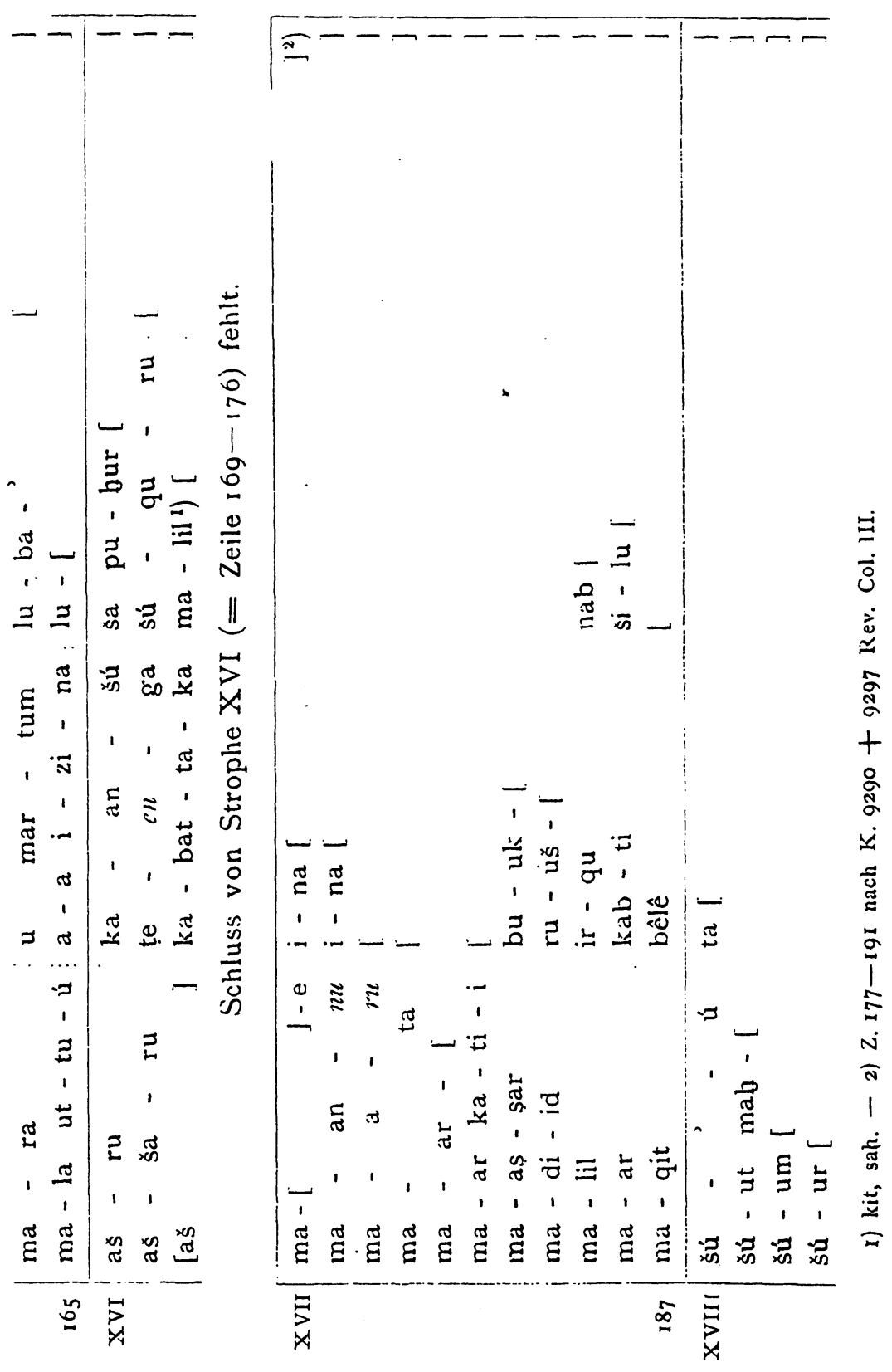




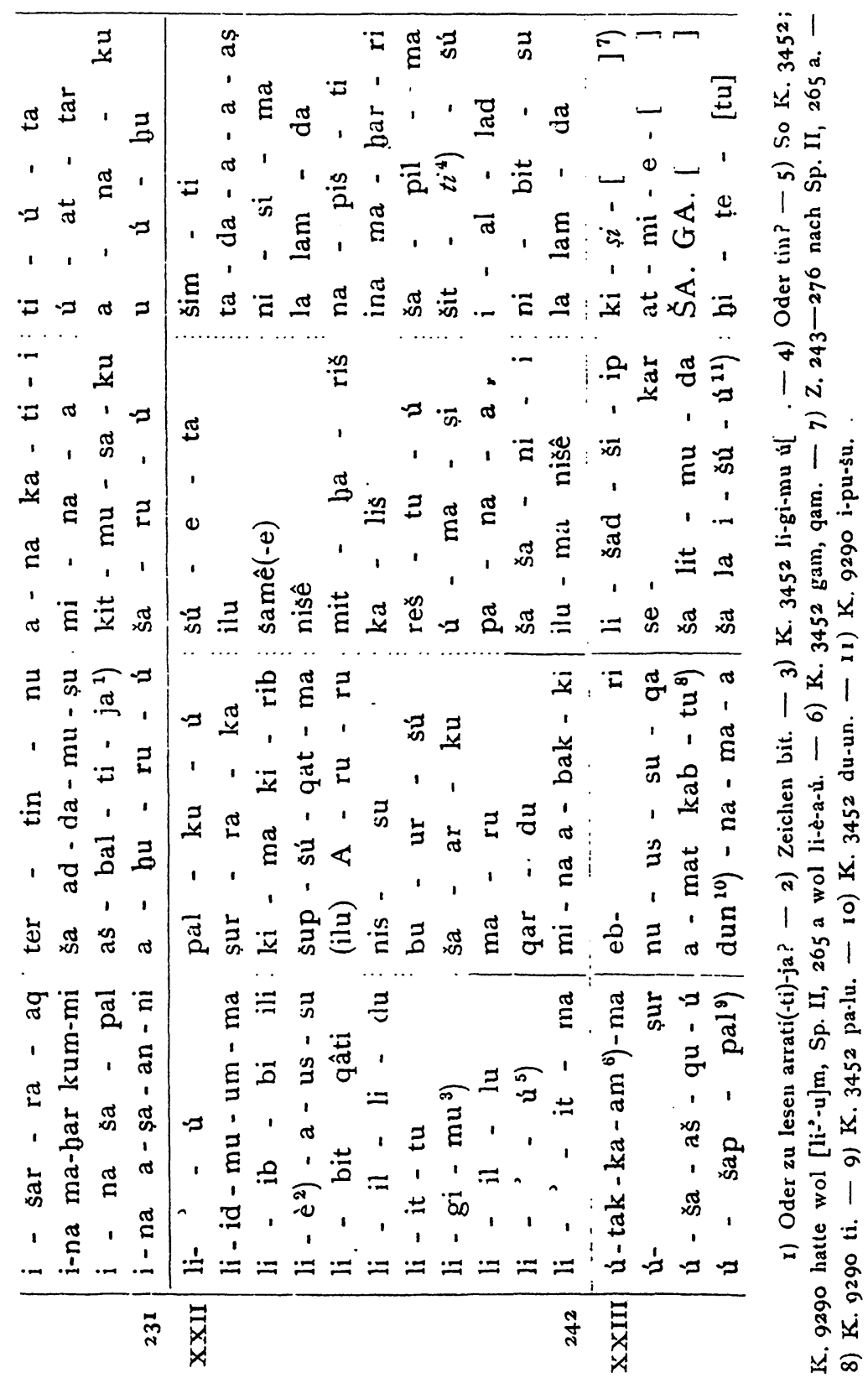




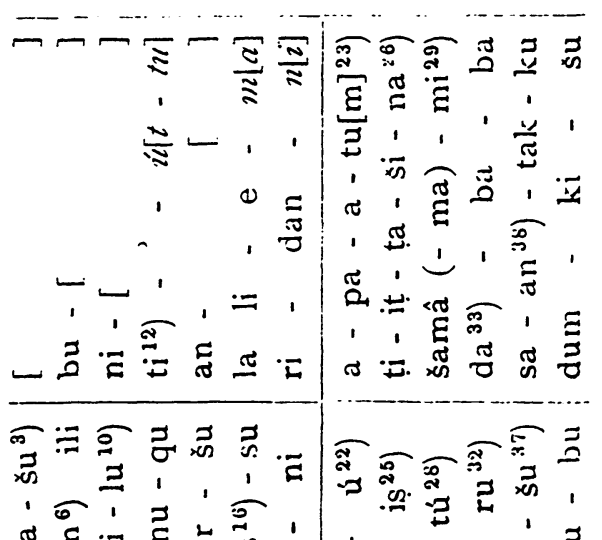
क

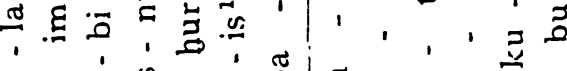

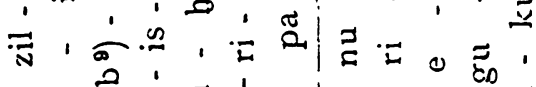
ส

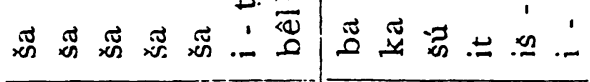

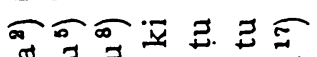

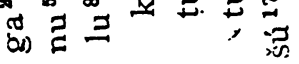

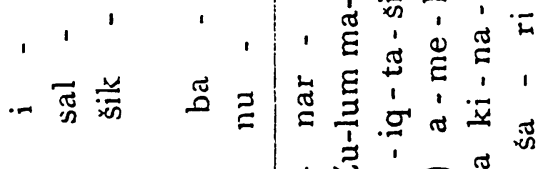

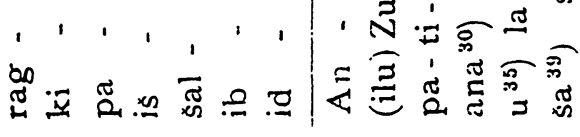

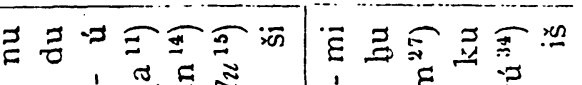

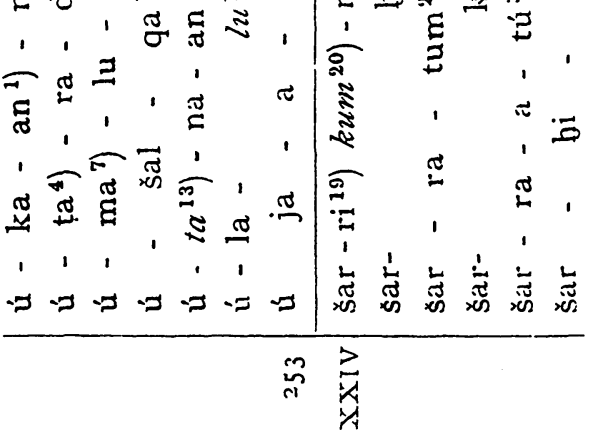

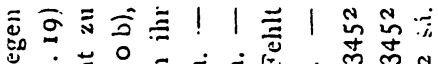

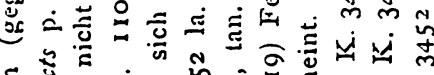

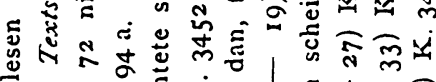

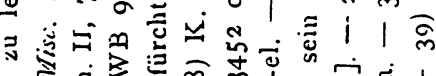

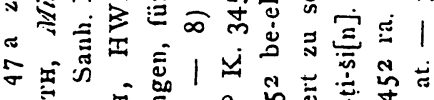

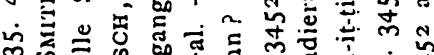

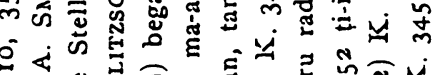

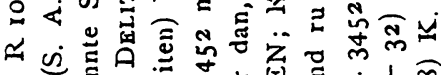

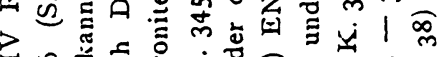
ఈ

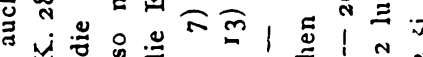

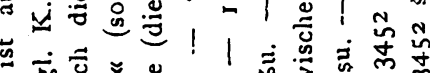

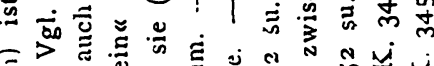
ఏ

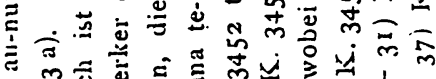

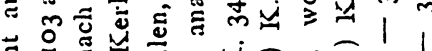

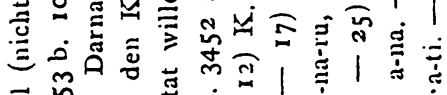

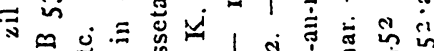

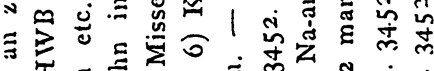

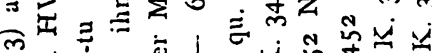
ल

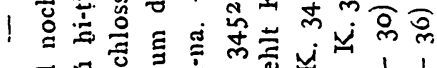

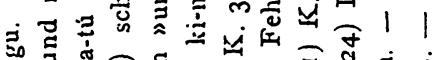

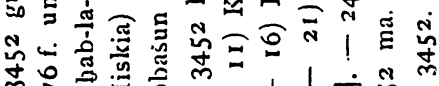

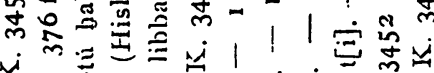

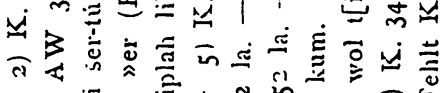

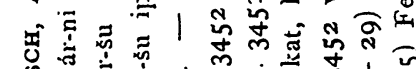

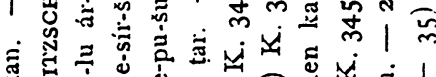

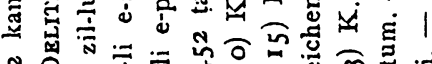

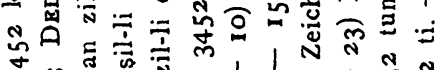

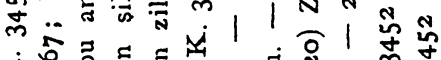

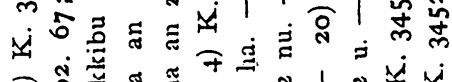
-

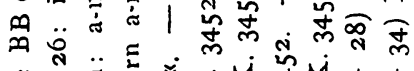
.

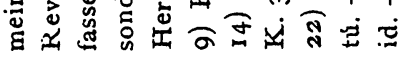




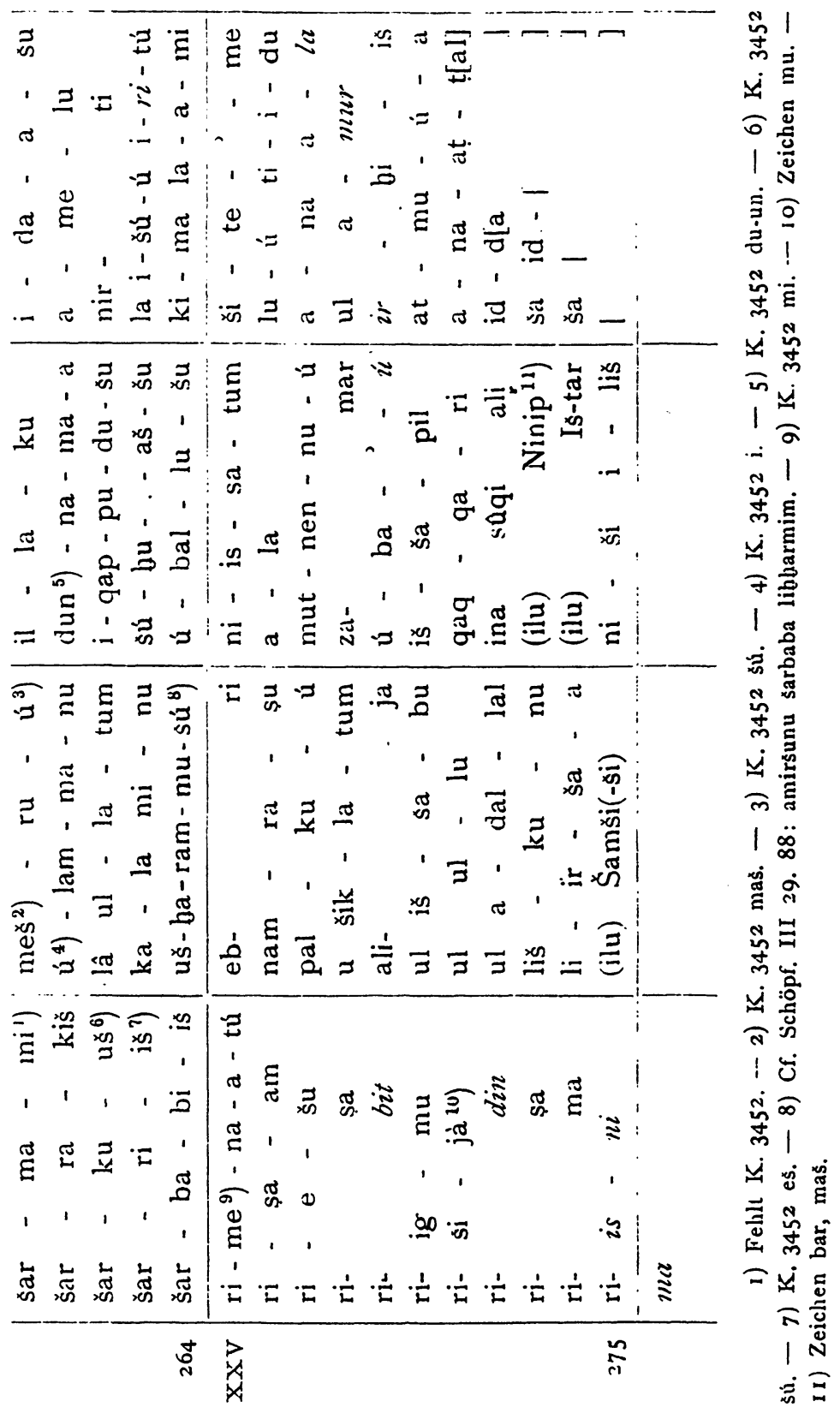


Aus der metrisch geschriebenen Tafel Sp. II, 265 a - nur von dieser mache ich im Folgenden Gebrauch lässt sich nun mit Leichtigkeit eine Reihe von Gesetzen für die babylonische Metrik ablesen:

Im Allgemeinen stellt ein einzelnes Wort (Substantiv, Adjectiv, Verbum) zugleich auch I Hebung dar, so dass ein Vers mit 4 Hebungen im Allgemeinen auch 4 Wörter enthält.

Dazu treten aber folgende Einschränkungen:

1) An das folgende Wort lehnen sich an, ohne eine eigene Hebung $z u$ bilden: das Relativpronomen ša (Z. 4 . 1 2. 23. 24. 241. 245-251. 259), Präpositionen (ultu ulla 17 , ana surri 26 , ana nišbê $3 \mathrm{I}$, ana amelût 257 , kîma lâmi 264, ana âla 267 , ina sûq âli 272), die Copula u (30. 253. 258. 268), die Negationen lâ (262. 263) und ul (268. 270-273) und die Wunschpartikel lû (266).

2) Eine status-constructus-Kette repräsentirt meistens nur I Hebung (uruh mûte 16, nâri hubur 17, pân ilima 2 I, pâliḩ Ištâr 22, gibiš tâmtim 24, zablat nišê 32 , amât kabtu 245, bêl pâni 253, šarri kummi 254). Doch fallen zuweilen auf eine solche auch 2 Hebungen, indessen, wie es scheint, vor allem nur in dem Falle, wenn das zweite Substantiv ein Pronominalsuffix hat (bal tahrûa II, narâm | libbuka 13, namratum | zîmuka I5, sekar | atmê[a] 244, kâriṣ țițašina 255; vgl. aber auch lumnu (Var. lumun) libbi 8).

3) Auch $z$ wei Partikeln vor einem Worte oder eine Partikel vor einer status-constructus-Kette bedingen nur eine Hebung (u lâ kênâtu 258 , ša lâ išû 246 , ša țêm ili 248 , ina sûq âli 272 ).

4) Zwei eng zusammengehörige Begriffe können, selbst wenn sie durch die Copula verbunden sind, unter eine Hebung fallen (abi u bânti I I).

5) Ein Vocativ kann, wie es scheint, eventuell einem Verse eingefügt werden, ohne für die Zählung der Hebungen in Betracht zu kommen. Cf. dafür vielleicht ebrî 
in L. 23. 25 gegenüber dem als eigene Hebung gezählten ebrî in 12.243.

Wie man sieht, findet die von mir in Bd. VIII, I $23 \mathrm{f}$. nach dem Vorgange Gunkel's aufgestellte Behauptung über die Vereinigung mehrerer eng zusammengehörender Wörter unter einer Hebung an dem metrisch geschriebenen babylonischen Originaltext ihre volle $\mathrm{Be}$ stätigung.

Noch bemerke ich. für den obigen Text, dass sehr wahrscheinlich stets 2 Verse eine Strophe bilden, während je der letzte, I I. Vers für sich allein steht.

Endlich ist es so gut wie sicher, dass die 25, je I I mal wiederholten, Anfangssilben des ganzen Textes ein Akrostichon bilden. Die Existenz solcher Akrosticha im Babylonischen ist ja durch K. 8204, wie BEzold, Catalogue p. 905 gesehen, sicher bezeugt. Auch DT. 83 (Pinches, Texts i $\mathrm{f}$.) liegt wol sicher ein Akrostichon vor. ${ }^{\mathrm{I}}$ ) Leider lässt sich bei dem defecten Zustande unseres Textes das Akrostichon noch nicht ganz herstellen. Man erhält, falls meine Zusammensetzung des Textes auch im Einzelnen ganz richtig ist, für dasselbe folgendes Schema:

$\begin{array}{cccc}\text { Col. I } & \text { Col. II } & \text { Col. III } & \text { Col. IV } \\ \text { I a } & & & \\ \text { II na } & \text { IX [ ] } & \text { XVI aš } & \text { XXI i } \\ \text { III ku } & \text { X [ ] } & \text { XVII ma } & \text { XXII li } \\ \text { IV [ ] } & \text { XI [ ] } & \text { XVIII sú } & \text { XXIII ú } \\ \text { V [ ] } & \text { XII ub } & \text { XIX ka (?) } & \text { XXIV šar } \\ \text { VI gi } & \text { XIII bi } & \text { XX ša } & \text { XXV ri } \\ \text { VII i] } & \text { XIV [ ] } & & \\ \text { VIII ki } & \text { XV ma } & & \end{array}$

Da die drei ersten Strophen anâku »ich « ergeben, so ist es verführerisch, anzunehmen, dass irgendwie der Name des Dichters mit nachfolgender Standesbezeichnung in dem

I) S. auch m. Catal., p. 1549. - Bez. 
Akrostichon enthalten sei etwa wie Valekius Hekberger sich in dem Kirchenliede Valet will ich dir geben verewigt hat, oder wie, um an ein näher liegendes Beispiel zu erinnern, nach LAGARDE in den alphabethischen PSs. 2522 und 3423 ein ברהזית nach Gonkel in dem alphabethischen Gedichte Nah If. in $2_{3}$ ein Sir. $5^{I_{30}}$ ein עבר als Verfassername versteckt sein soll (s. GunkeL in ZATW ${ }^{1324}$ ). Vielleicht ist es aber doch besser, $a-n a$ als die Präposition $a n a z u$ fassen und dann etwa zu ergänzen: a-na Ku-[ur-nu-]gi, wofür in Z. Io des Textes ein Anhalt gesucht werden könnte. Der Schluss des Akrostichons ergibt: ma-as-ma-šú-ka šá i-li ú šar-ri.

Leipzig, im November 1894. 
Whitores sur babylozisshen Metsik.

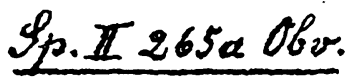

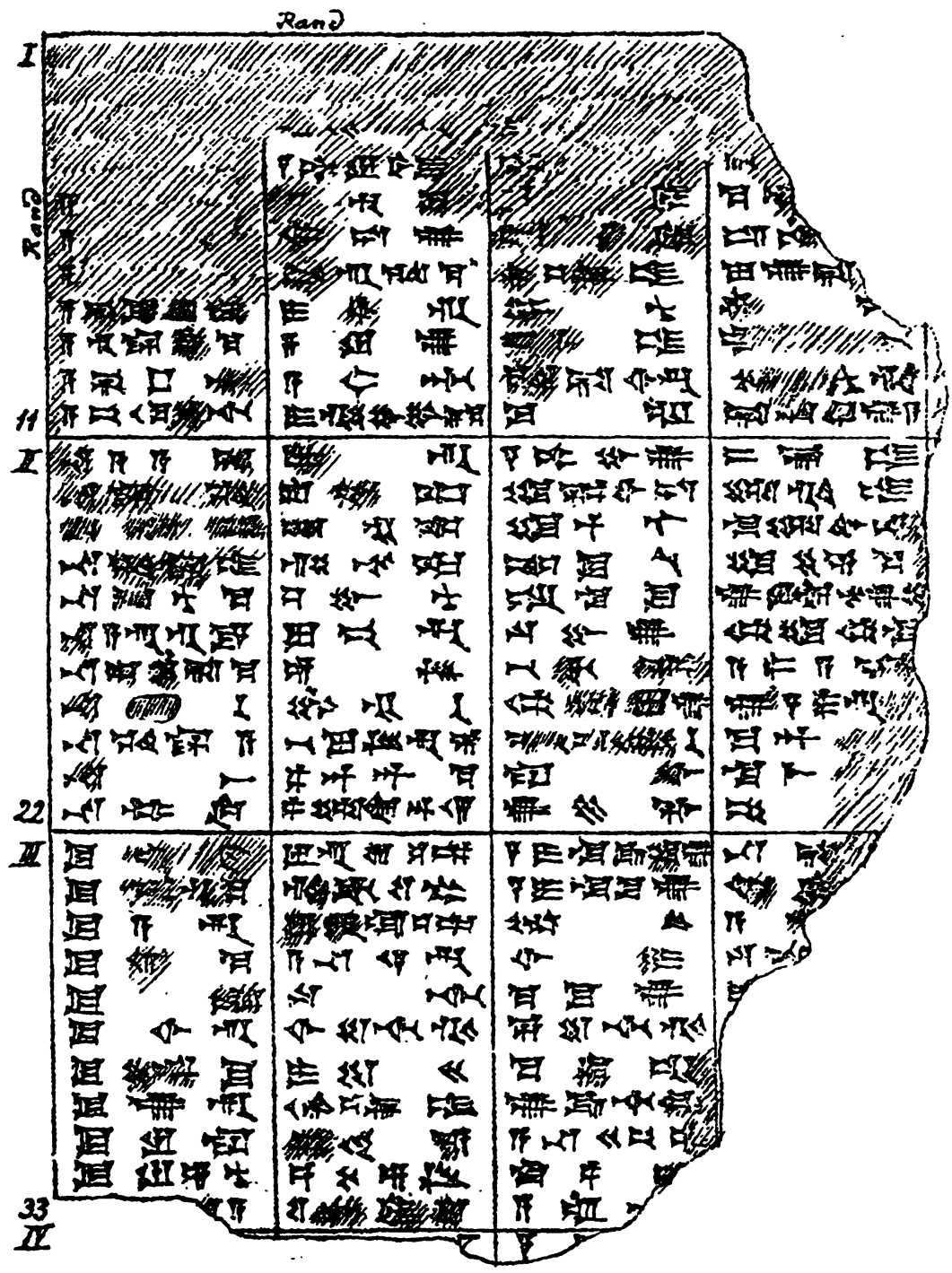

,Zeitschr.f.Assyriolegic, X. 


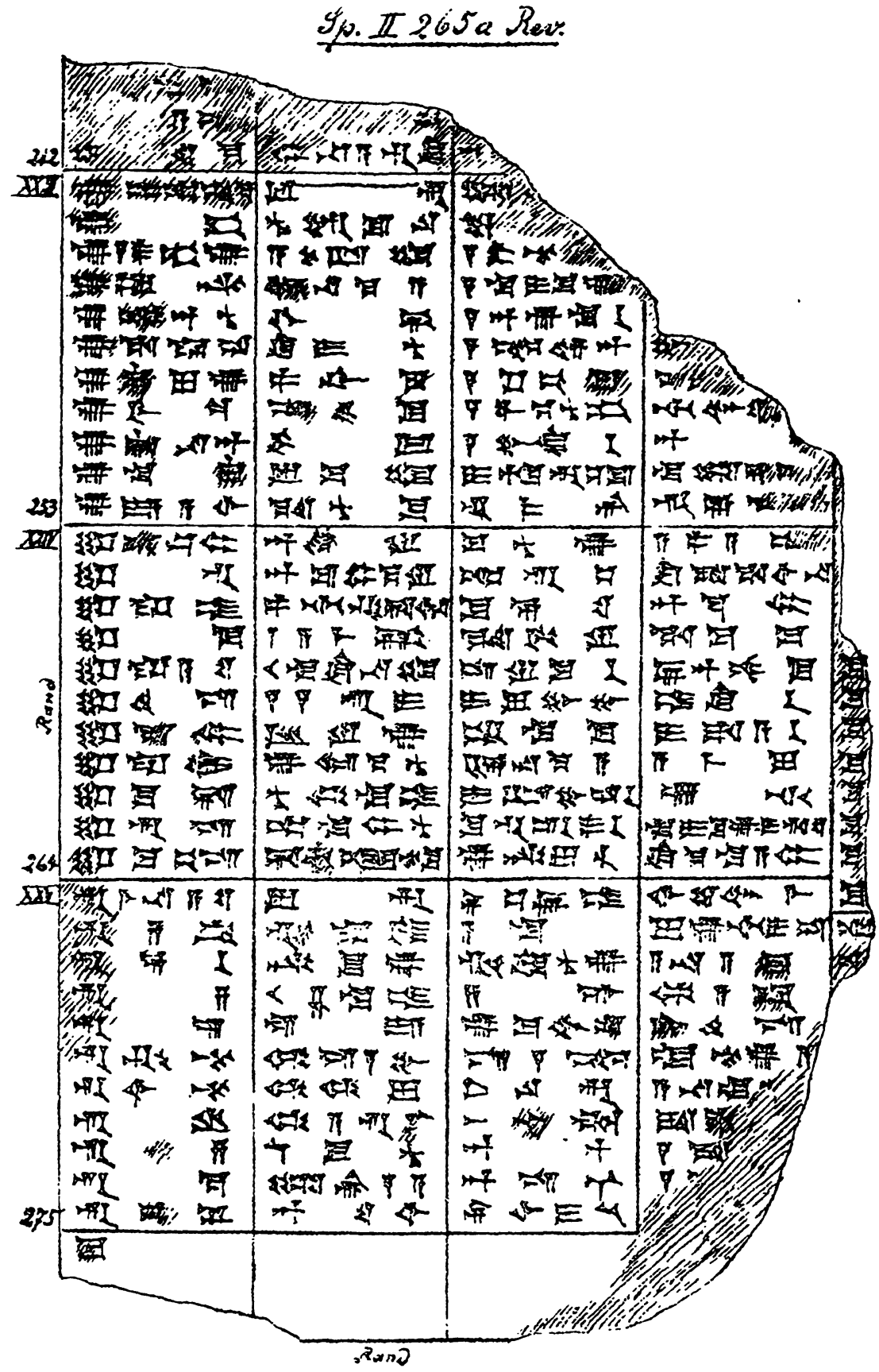


Fiseiteres zer babyforischen Netrik.

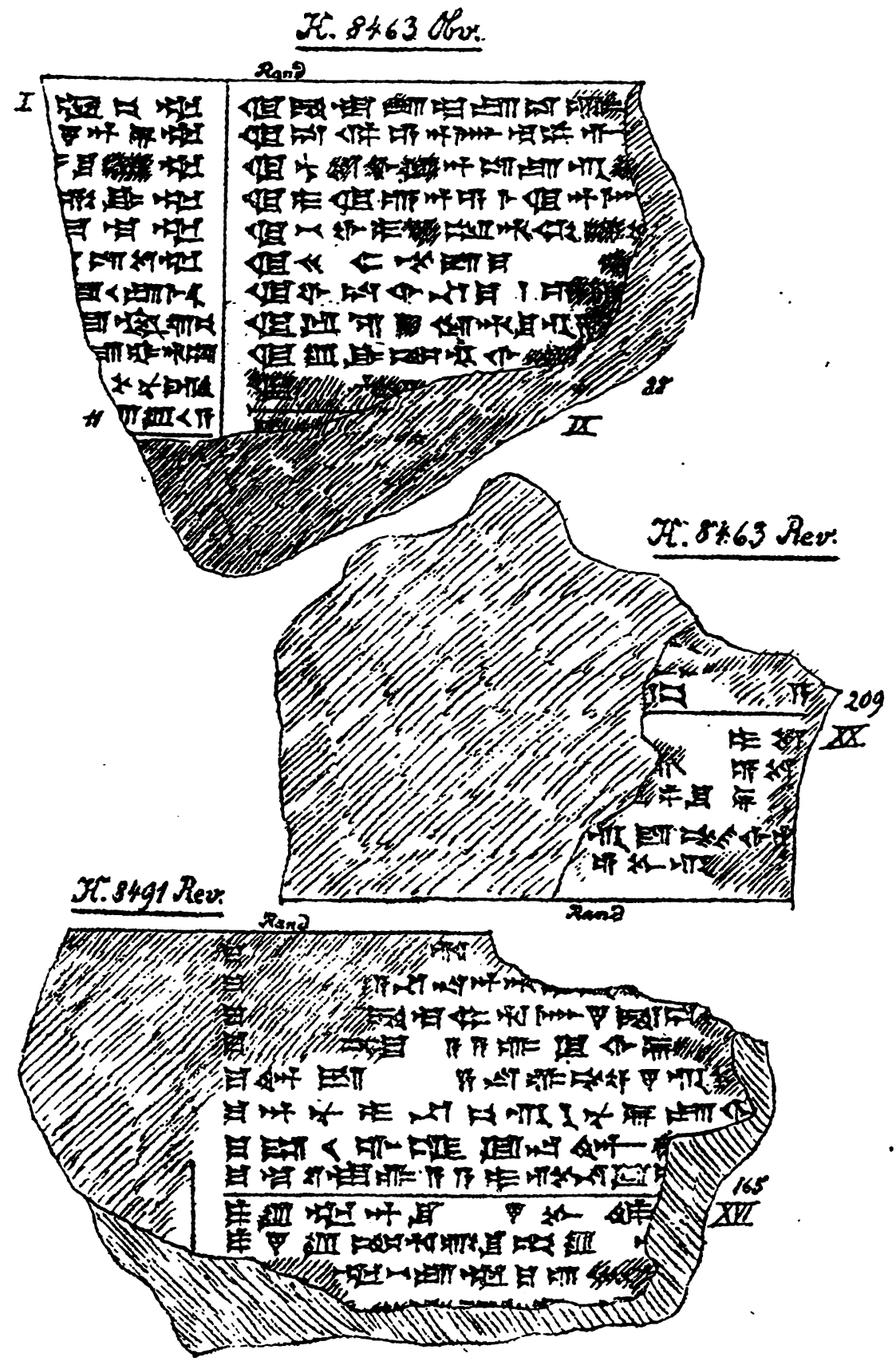




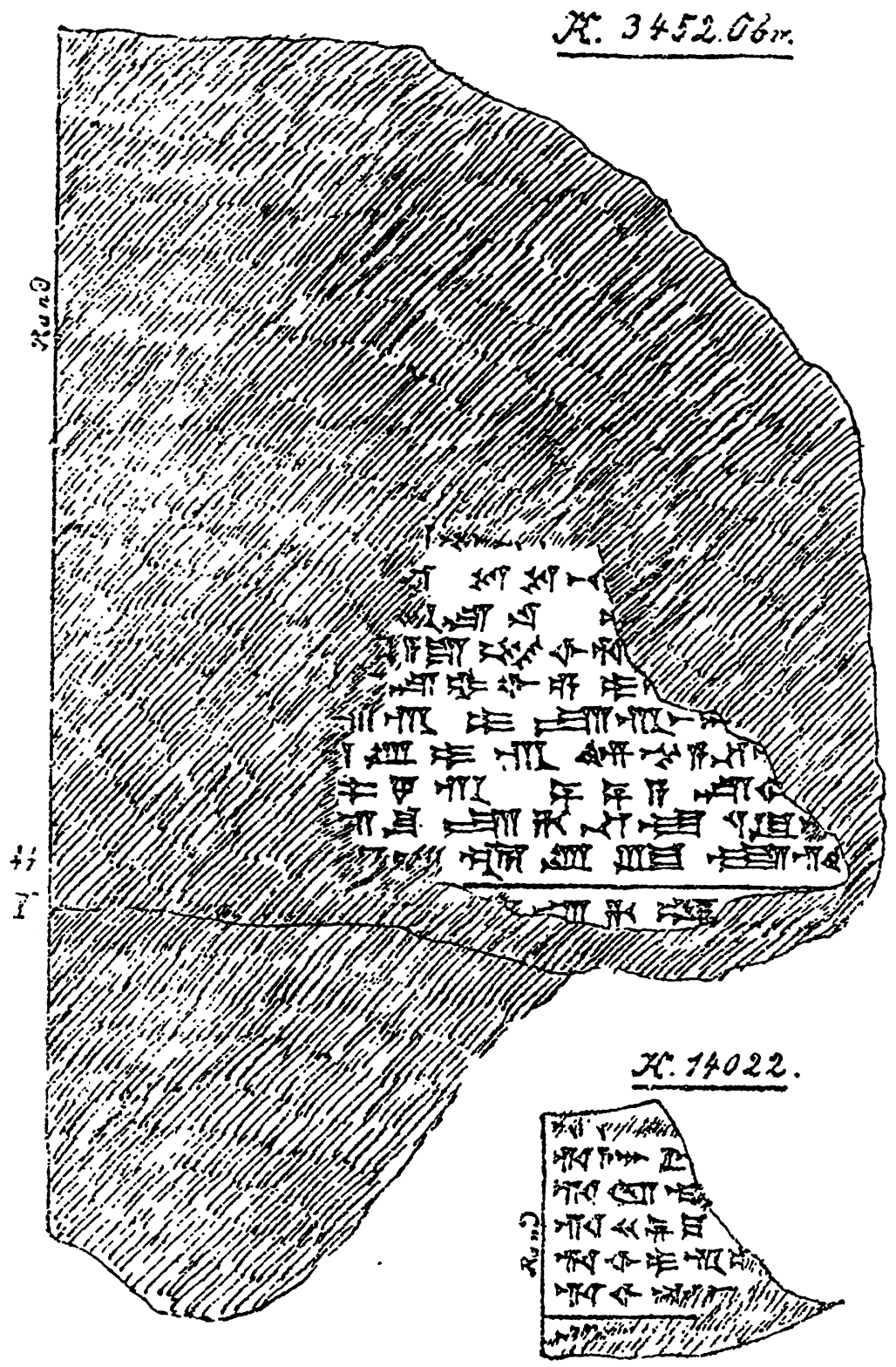


Weiteres zut babylonischen Metrik.

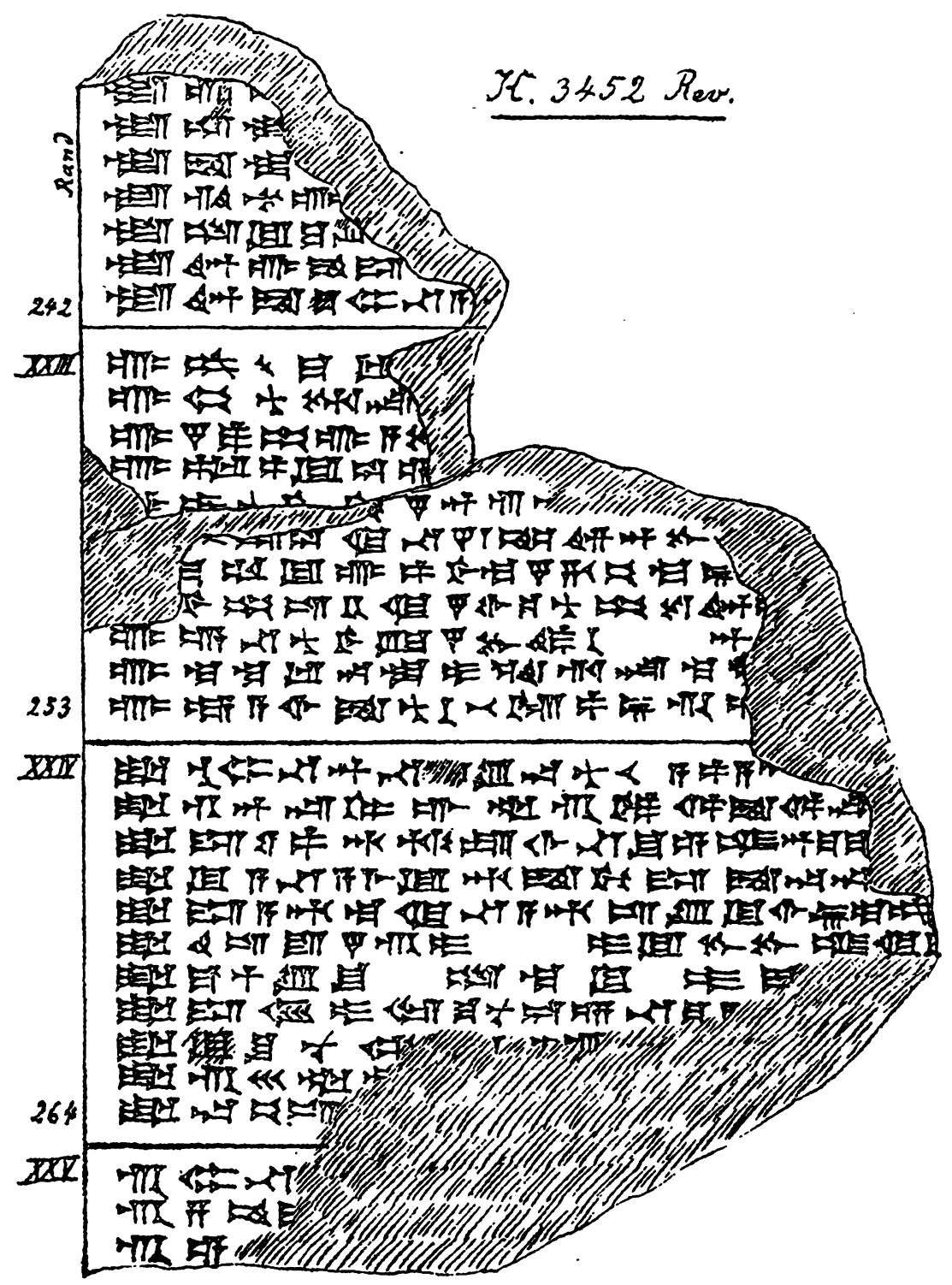




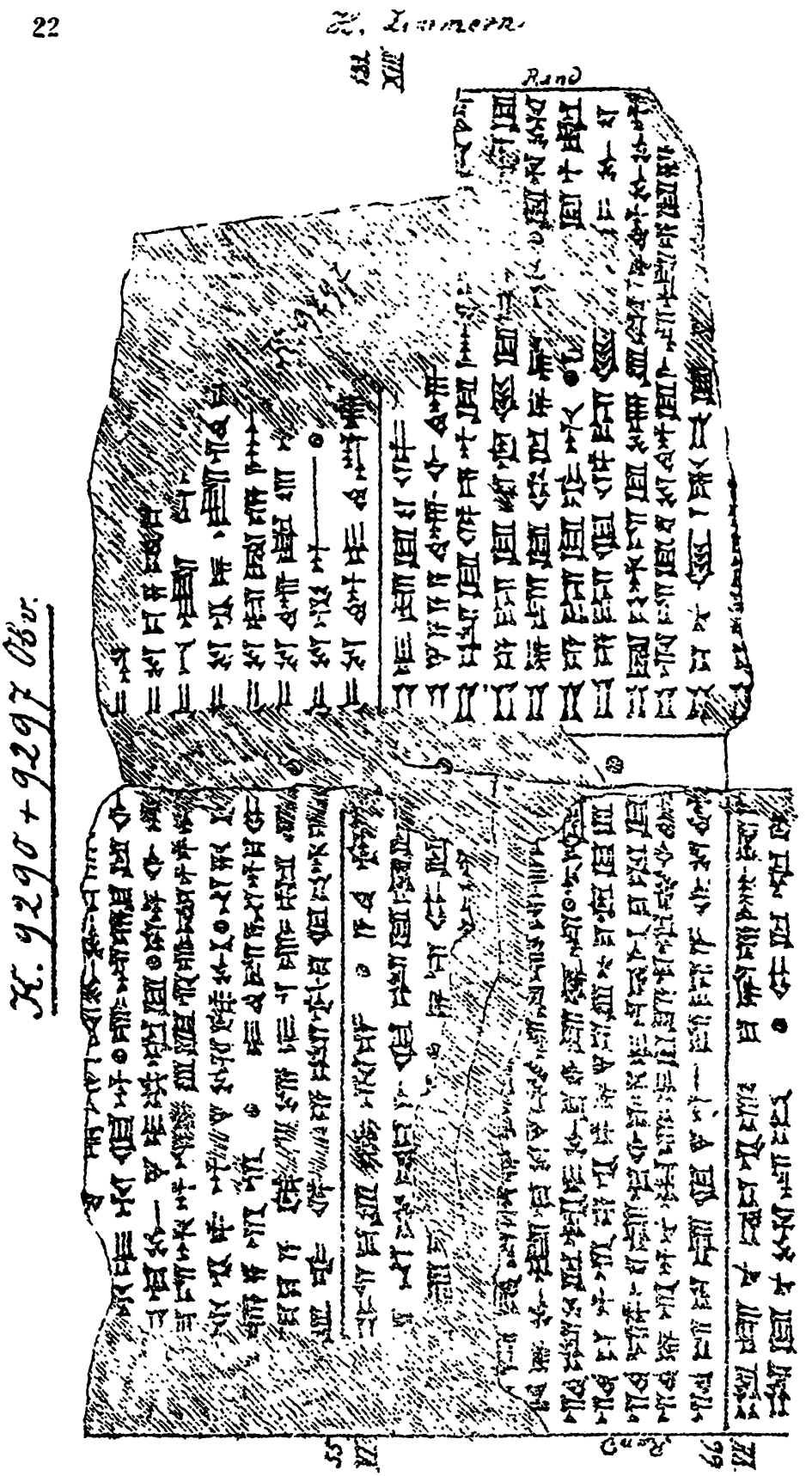


Whiteres zees babylonischen Hetix:

\section{$\mathcal{K}^{*} .9290+9297060$. (Fortserizung.)}

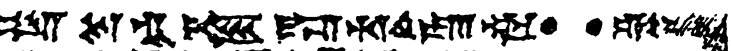

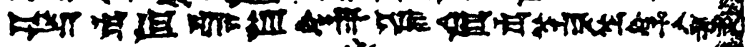

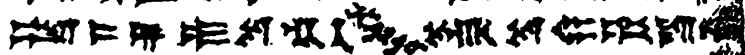

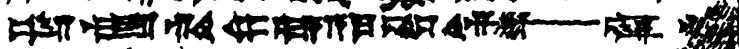

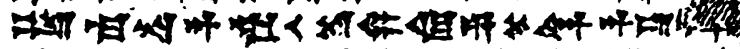

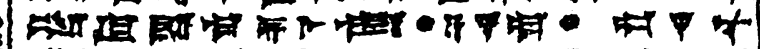

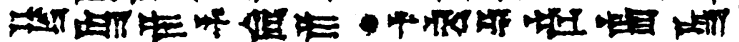

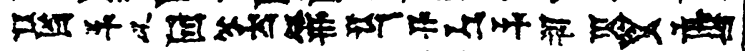

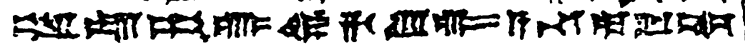

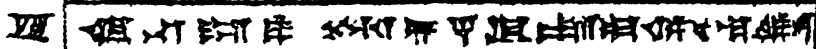

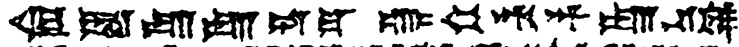

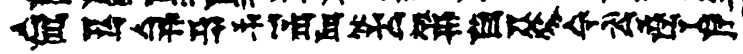

$\operatorname{Ran} 2$

Kr. $2290+9297$ Reverow

Rent

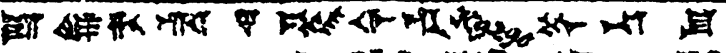

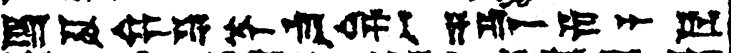

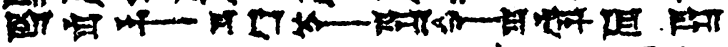

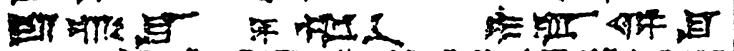

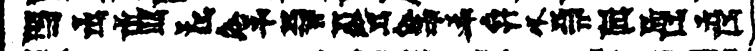

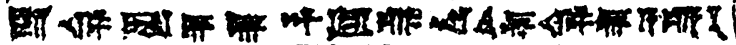

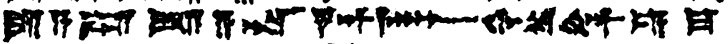

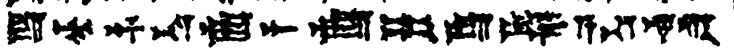

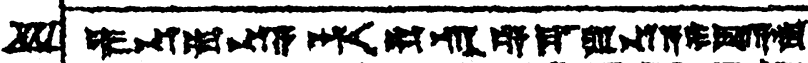

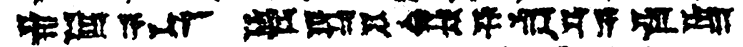

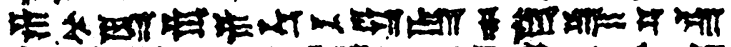

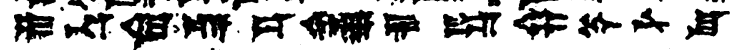

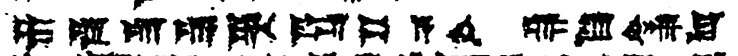

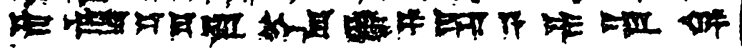




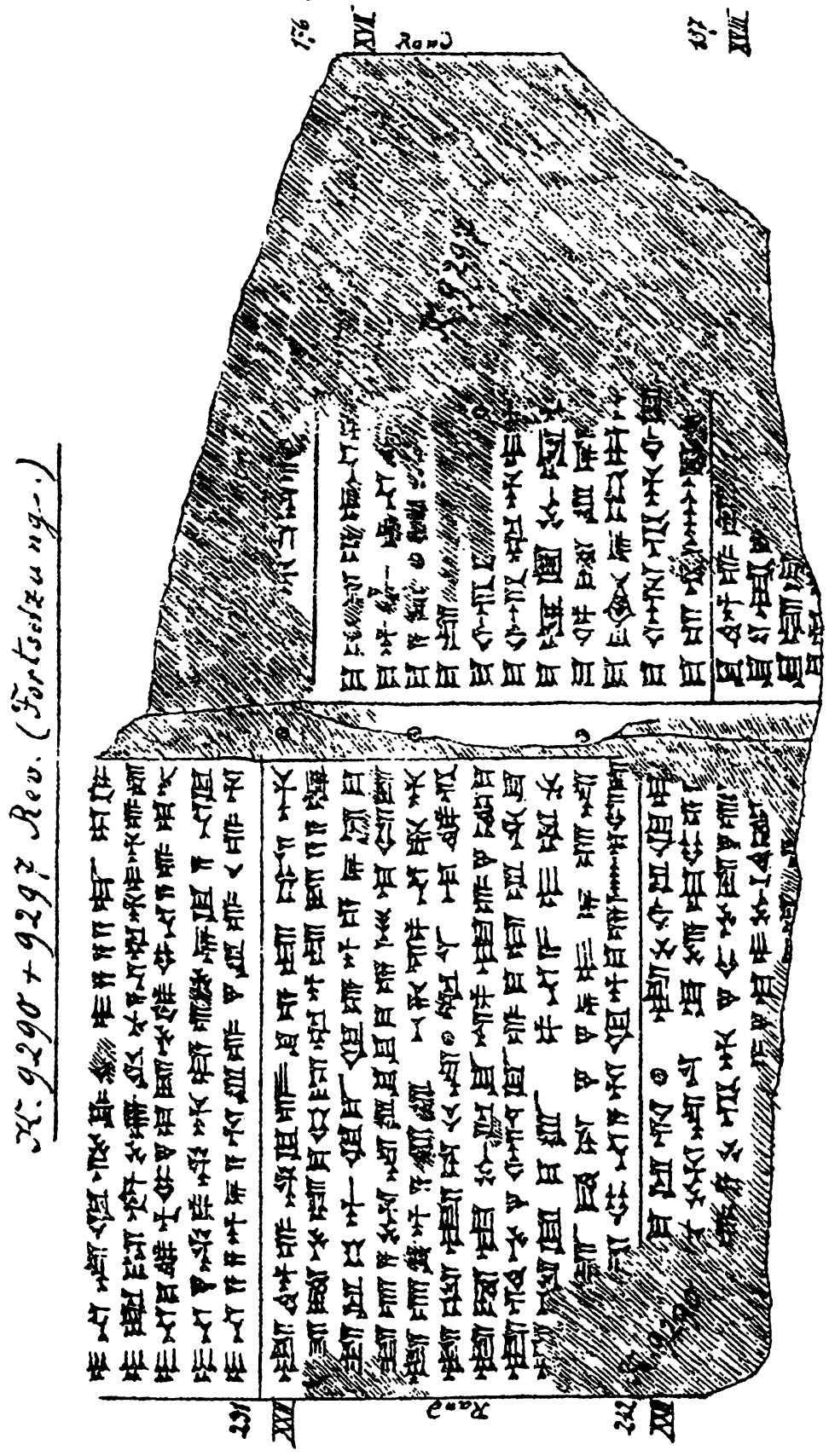

